\title{
Visual attention within and around the field of focal attention: A zoom lens model
}

\author{
CHARLES W. ERIKSEN and JAMES D. ST. JAMES \\ University of Illinois, Urbana-Champaign, Champaign, Illinois
}

\begin{abstract}
The operation of attention in the visual field has often been compared to a spotlight. We propose that a more apt analogy is that of a zoom or variable-power lens. Two experiments focused upon the following questions: (1) Can the spatial extent of the attentional focus be made to vary in response to precues? (2) As the area of the attentional focus increases, is there a decrease in processing efficiency for stimuli within the focus? (3) Is the boundary of the focus sharply demarked from the residual field, or does it show a gradual dropoff in processing resources? Subjects were required to search eight-letter circular displays for one of two target letters and reaction times were recorded. One to four adjacent display positions were precued by underlines at various stimulus onset asynchronies before display presentation. A response competition paradigm was used, in which the "other target" was used as a noise letter in noncued as well as cued locations. The results were in good agreement with the zoom lens model.
\end{abstract}

Much of our information about the operation of attention in the visual field has been obtained from visual search tasks or modifications of this procedure. When visual displays are presented at durations too brief to permit saccadic eye movements, accuracy in identifying targets in the display or the time required to do so can be presumed to reflect underlying visual attentional processes.

Two salient findings have emerged from this research on visual attention. One finding is that under certain conditions the resources of the attentional system seem to be distributed evenly over a display, with parallel processing of the display items (C. W. Eriksen \& Spencer, 1969; Kinchla, 1974; Shiffrin \& Gardner, 1972; Shiffrin \& Geisler, 1973), whereas under other conditions a focused or serial scanning of a display seems to occur (C. W. Eriksen \& Yeh, 1985; Hoffman, 1978, 1979; Jonides, 1983; Prinzmetal \& Banks, 1983).

The second major finding is that attention can apparently be concentrated or directed to a specific location in a display by a precue that occurs as short as $50 \mathrm{msec}$ before display onset. This precuing results in appreciably faster target identification or detection. C. W. Eriksen and his associates (Colegate, Hoffman, \& C. W. Eriksen, 1973; C. W. Eriksen \& Colegate, 1970; C. W. Eriksen \& Collins, 1969; C. W. Eriksen \& Rohrbaugh, 1970) have extensively investigated the manipulation of attention by precues. They have employed circular letter arrays centered on a fixation point and used a bar marker to cue the location of the target letter. Both accuracy in identifying the target letter and reaction time (RT) have

This research was supported by Public Health Service Research Career Program Award K6-MH-22014 to the first author and by United States Public Health Service Research Grant MH-012006, also to the first author. Requests for reprints should be sent to Charles W. Eriksen, Department of Psychology, University of Illinois, Urbana-Champaign, 603 East Daniel, Champaign, IL 61820. been employed as dependent variables. Speed in identifying the target letter increases as the cue precedes the display by increasing intervals, the function becoming asymptotic when the cue leads the display by about $200 \mathrm{msec}$. The facilitation in RT depends upon the total number of letters in the display. The greater the number of noise letters in the display, the longer the RT and the greater the decrease by precuing. These RT differences for different-sized displays are not completely eliminated even with a 200 -msec precue.

A particularly interesting finding has been made with single-letter displays. Here a precue that designated the exact location in the visual field where a target letter would occur led to a significant facilitation in RT for identifying the letter (C. W. Eriksen \& Hoffman, 1973, 1974; Hoffman, 1975). In these experiments, one of two possible target letters appeared in one of eight possible locations on a circular display centered on the fixation point. Only the single target letter appeared with no accompanying noise or extraneous letters. If the position in which the target letter would appear was precued by a bar marker 50 to $100 \mathrm{msec}$ before the letter appeared, a 30- to 40 msec improvement in RT was obtained. Similar results have been obtained with a detection task by Posner, Snyder, and Davidson (1980).

Capacity, or resource, models have been used to describe these spatial characteristics of visual attention. Attention can be conceived of as a limited supply of processing capacity, or resources, that can be allocated in varying amounts to different tasks (Kahneman, 1973; Wickens, 1978) or to different locations in the visual field (C. W. Eriksen \& Hoffman, 1972; Jonides, 1980, 1983; M. L. Shaw, 1978; M. L. Shaw \& P. Shaw, 1977). According to these models, parallel search of visual displays is the result of an even allocation of attentional processing capacity to all display positions. If the discrimination 
is simple enough that these distributed resources can handle the processing, evidence for parallel search is obtained. If, however, the discrimination requires greater resources, then resources are concentrated and display locations are searched serially. Precuing expedites target processing by allowing attentional resources to concentrate on the spatial location before the display occurs. This speeds identification of the target by giving the system a head start on concentrating processing resources on the designated location, and by concentrating rather than distributing resources.

Resource models vary in terms of whether they permit attentional resources to be allocated simultaneously in different amounts to different locations in the visual field (M. L. Shaw, 1978; M. L. Shaw \& P. Shaw, 1977) or whether they conceive of resources as being restricted to either a distributed or a focused state (Jonides, 1983). M. L. Shaw and P. Shaw (1977) varied the probability with which targets appeared in different display locations and found that recognition accuracy varied directly with the probability of target occurrence. M. L. Shaw (1978) also found that reaction time in target identification varied directly with the probability that a target would appear in a particular display location. These results are consistent with an interpretation that different amounts of attentional capacity can be allocated to different positions in the visual field simultaneously. However, this interpretation is not unequivocal. It is possible that the correspondence between choice RT and target location probability could have been due to the subjects' probability matching over trials. The same results could have been obtained had the subjects taken a single-focus attentional approach and varied the probability with which it was directed to different display locations over trials in accord with the probability of target occurrence.

The probability matching interpretation was supported by Jonides's (1983) research. Jonides used a choice RT test with circular arrays of eight letters. Target location was designated by either efficient or inefficient precues, both of which had only $50 \%$ validity. Detailed examination of RT distribution characteristics for valid and invalid trials supported an interpretation that on some trials the subjects used a distributive approach to the display in which all displayed items were processed in parallel, whereas on other trials they used a focused attentional approach to the precued display location. There was no evidence in the data that the subjects were able to concentrate attentional resources to several display locations simultaneously.

Jonides (1983) proposed a two-process model of attentional distribution, which posits that, in one mode of operation, attention is uniformly distributed over all possible display locations and the target is searched for in parallel. In the other mode, subjects can choose to focus their attention on the precued location. In this case, the concentrated attentional resources lead to more rapid processing of the target and faster RT. If the precue is invalid, an appreciable cost is involved, and the data in- dicate that the subject then reverts to the distributive approach or parallel searching of the remaining display locations.

C. W. Eriksen and Yeh (1985) followed up on Jonides's (1983) experiment. They used a very similar task and procedure but used only an efficient precue that varied in validity from $40 \%$ to $100 \%$. They also used a no-cue control condition and introduced the innovation of having a secondary target location that was diametrically opposite the primary precued location. Their results were in close correspondence with Jonides's $(1980,1983)$ findings and the data were well described by Jonides's twoprocess model. Their data were described quantitatively quite well by assuming that in the no-cue control condition their subjects used a distributed attentional approach with parallel processing of all display locations. With a precue, the subjects used a focused approach roughly in proportion to the cue validity for the primary cued location. On invalid trials when the target did not appear in the primary cued location and the subject had chosen the focused approach, the data analyses indicated that the subject then directed a focused attention to the secondary cued location. However, there was an appreciable cost associated with failure to find the target in the primary cued condition when the focused mode was employed. When the target appeared in the secondary location, mean RT was longer than in the noncued control condition. The data also suggested that once the subject had chosen the focused approach, he/she persisted in this method of serially scanning the display through the remaining three possible target locations or until the target was located. No evidence was found that subjects were able to divide their attention between different display locations simultaneously in keeping with the probability of target occurrence. In addition, the marked costs associated with an invalid cue were found to consist primarily of the time it took the subject to process a noise letter to the point at which he/she could decide it was not a target.

Although Jonides's two-process model provided a good quantitative description of the data, C. W. Eriksen and Yeh (1985) proposed some modifications in the model. Instead of conceiving of attention as capable of following two distinct modes of operation, a distributive and focused mode, C. W. Eriksen and Yeh proposed that the two processing modes of Jonides were actually poles on a continuum of attentional distribution in the visual field. At one pole, attentional resources can be uniformly distributed over the entire effective visual field, and at the other pole they can be concentrated or focused on an area as small as a fraction of a degree of visual angle (LaBerge, 1983). Instead of the analogy of an attentional spotlight, they suggested that a more appropriate analogy would be that of a zoom lens. C. W. Eriksen and Rohrbaugh (1970) and C. W. Eriksen and Hoffman (1972) had previously noted the similarity of some visual attentional phenomena to a zoom lens. With a zoom lens at a low power setting there is a wide field of view with no magnification of the objects within that field. There is, therefore, little dis- 
crimination of detail. As the power of the lens increases, the field of view constricts, with a concomitant increase in the resolving power for detail of the objects still remaining within the field. With a perfect lens system, there would be a complete tradeoff in terms of the loss of field of view with the corresponding increase of magnification or accessibility of detail for objects remaining within the field.

In this analogy, a low power setting of the zoom lens would be the equivalent of an even distribution of the attentional resources over the effective visual field. This would result in parallel processing of the stimuli within this field, but due to the low density of resources, the rate of processing for items in the field would be slow and there would perhaps be a limit on the amount of information that could be extracted from any given object in the field with this distributed resource approach. If the analogy is valid, attentional resources could be concentrated in very small spatial extents in the visual field. The smaller the spatial extent, the greater the concentration of resources, with a faster rate of information extraction and the capacity to resolve finer and finer detail or extract more information about the stimuli within the effective attentional field.

We do not as yet have sufficient empirical data concerning the operation of visual attention to determine how apt the zoom lens analogy is. For the present, we consider it a source of working hypotheses to guide research and a framework within which to describe results. The analogy suggests a number of questions that can be asked about the operation of attention in the visual field. In the present research we addressed three main questions: (1) Can the focus area of attention, measured in terms of visual angle subtended in the visual field, be varied continuously from an area of less than $1^{\circ}$ of angle to an area subtending several degrees? (2) As the area of the attentional focus increases, is there a corresponding decrease in attentional resources deployed to each object encompassed within the focus area? (3) Is the boundary of the focus sharply demarked from the residual field, or does it show a gradual dropoff in processing resources?

With respect to the first two questions, the evidence we have summarized above is quite clear in indicating that visual attention can operate either in a focused approach or in a distributive approach, but this does not necessarily imply that it can assume various sizes in between. The zoom lens analogy would also require that there be a tradeoff between field size and the effective concentration of processing resources. Theoretically, the focus size could be considered to vary from an area subtending less than $1^{\circ}$ of angle to the full size of the visual field, but the nature of the retina itself effectively limits this. As C. W. Eriksen and Hoffman (1972) have pointed out,

The lack of resolution of detail for objects presented on the peripheral retina would provide very definite limits upon the level of information processing or extraction that could occur without a corresponding change in the eye's fixa- tion. The duration of attention to stimuli in the peripheral field would be quite short since the available information would be rapidly exhausted. (p. 204)

There would appear to be little value in using a highly focused attentional capacity on peripheral areas, where so little detail resolution is provided by the visual sense organ that the concentration of processing capacity is essentially wasted. We might expect, therefore, that variations in the focus size of attention would primarily occur within the foveal and parafoveal areas, where enough detail or information is provided from the sense organ to utilize concentrated processing capacity.

LaBerge (1983) proposed that the attentional focus can vary in size, but instead of a zoom lens analogy he used a spotlight conception. The size of the spotlight can vary and, consistent with the zoom lens model, processing capacity or speed decreases with increased size of the attentional spotlight. His experimental findings suggest that attention can be prefocused to an area encompassing one letter (less than $1^{\circ}$ of visual angle) or expanded to include a five-letter word. In his experiment more rapid RTs were obtained for a focus size encompassing the five-letter word than for the smaller focus size. This is the reverse of what would be anticipated if processing capacities were more concentrated and performance improved with the smallersized attentional focus area. However, the discriminations involved in the two tasks and the decision processes were quite dissimilar, so that performance on the two tasks was not directly comparable. Thus the question of whether processing capacity is more concentrated with the smaller focus area remained untested.

Egeth (1977) reported an experiment that directly tested whether focus size could be experimentally varied with a concomitant reciprocal variation in processing speed. He used a large and a small visual extent in which targets could occur and measured recognition latency for a central location that was common to both focus sizes. Consistent with a zoom lens analogy, he found that recognition latency for the common central location was more rapid with the small than with the large extent. Similar findings were reported by Beck and Ambler (1973), who found that discrimination accuracy decreased when the spatial uncertainty of the target increased.

Other research, however, has failed to support a relation between the spatial uncertainty of a target and discrimination or detection accuracy. Lappin and Uttal (1976) required subjects to detect the presence of a line of dots embedded in a random dot noise display. They found that the percentage of correct detections decreased as the spatial location of the target increased in uncertainty, but the rate of decrease was predicted by a simple assumption that an increase of the spatial extent provided a greater opportunity for confusing a possible target with noise. Shiffrin, McKay, and Shaffer (1976) came to a similar conclusion. In one experiment they had subjects detect the presence of a dot that might appear, in different conditions, only in the center of an array, in one of 9 loca- 
tions distributed around the center, or in one of 49 locations distributed around the center. They reported that the number of potential spatial positions did not appear to influence detection sensitivity. However, Keren and Skelton (1976) reevaluated Shiffrin et al.'s findings and found evidence that attentional focus may have been operating in the experiment.

The conflicting results of the above experiments may reflect a difference in the dependent variable. The RT measure used by Egeth (1977) may be a more sensitive measure of the degree of concentration of attentional resources than is detection accuracy. The accuracy experiments produce data-limited displays by using brief exposure durations, but there is evidence that even though a visual exposure may be only $25 \mathrm{msec}$ in duration, it persists for 80 to $120 \mathrm{msec}$ as a visual event or as an icon (DiLollo, 1977). Due to this persistence, and to the fact that detection does not require a high level of processing, a briefly exposed stimulus requiring detection may be quite insensitive to the degree of concentration of attentional resources. Also, the duration of the visual event may be long enough to permit attention switching or focusing. A more sensitive measure of differences between distributed and focused attention might be the time required to make the detection.

An expectation that the attentional resources available for processing individual stimuli in the focus would decrease as the size of the focus increases makes the implicit assumption that the subject is allocating all possible attentional resources to the task. We believe that there are few, if any, experimental tasks for which this assumption would be plausible. Instead, we would posit a principle of optimal attention allocation. Performance level on tasks depends upon variables and processes other than attention. Sensory and motor limitations, as well as central processing mechanisms other than attention, set performance limits. Performance on a given task cannot be continuously raised by allocating increased attentional resources to the task. For a given subject and a specific task, there is an optimal level of attention. More resources will not improve performance.

We believe that extensive prior experience and the learning that occurs in the initial trials of experiments permit subjects to make good judgments about the optimal amount of attentional resources for a particular experimental task. Thus, in nearly all experimental situations, the subject should be conceived of as having a reservoir of attentional resources he/she can draw upon to apply to tasks as they become more attention demanding (i.e., are perceived by the subject to be able to benefit from more attentional resources). Attention requires effort, and most subjects operate on a conservation-of-effort basis. How much attention is allocated to the task will depend on the subject's experience with the task and on other motivational variables. A failure to find that the processing of individual stimuli in the focus area decreases in speed or efficiency as the area increases in size may thus be attributed to the subject's allocating more resources to the task as the task is perceived to be able to benefit from this increased allocation. If we apply this optimalallocation principle to attentional focus in the visual field, only under conditions in which the subject had allocated all possible resources to the attentional field would we be able to test the expectation from the zoom lens model that the density of processing resources decreases as the size of the attentional field increases.

If the attentional field has a locus in the visual field, it must also have a boundary. The nature of this boundary is of both theoretical and practical interest. The focus area could be sharply demarcated with a step-wise transition from high resource concentration to the remaining visual field with low residual processing capacity. Alternatively, the boundary could be comparable to William James's (1890/1950) phenomenal description of visual attention in which there is a focus, a margin, and a fringe. James's conception implies a gradient in which attentional resources decrease gradually from the focus area to the residual field. If there is such a gradient, does the slope of this gradient vary with the size of the focus field and with the field shape?

There is little empirical evidence to answer these questions. C. W. Eriksen and Hoffman (1973) found indications of a gradient extending to about a degree of angle on each side of the focused region. They used circular displays of 12 letters, consisting of $H, A, M$, and U. Subjects responded with a lever movement in one direction when a letter designated by a bar indicator was a member of the set A-U and in the opposite direction when it was from the set $\mathrm{H}-\mathrm{M}$. The experimental variables were the stimulus onset asynchrony (SOA) by which the bar indicator preceded the display and whether the target letter was flanked by letters of the same or the opposite response set. Even when the target location was precued by the bar indicator as much as $\mathbf{3 5 0} \mathrm{msec}$ before display onset, a response-competitive noise letter in an adjacent position $\left(.5^{\circ}\right.$ removed) produced significant impairment in RT. A response-competitive letter $1^{\circ}$ away produced less impairment, but still more than did one removed by $2^{\circ}$. Because the major purpose of this experiment was to investigate the possibility of response competition effects, the design did not permit a clear delineation of the gradient when opposite response letters were placed two positions away ( $1^{\circ}$ of visual angle removed). When this occurred, the position adjacent to the target was occupied by a response-compatible letter. Thus, for incompatible noise letters $1^{\circ}$ of angle away, the data were confounded with possible facilitating effects due to the presence of a compatible letter close to the target.

The questions and issues discussed above are not unique to a zoom lens model of visual attention. As we have seen, many questions are also raised by LaBerge's (1983) conception of a variable spotlight model. Whatever the con- 
ceptual framework, there are basic empirical questions concerning visual attention, questions addressed by the present experiments.

\section{EXPERIMENT 1}

\section{Design and Rationale}

In order to build upon and utilize the results of previous research to the greatest possible extent, the tasks and the visual displays used in the present investigation were either identical or highly similar to the tasks and displays used in considerable prior research (C. W. Eriksen \& Hoffman, 1974; C. W. Eriksen \& Yeh, 1985; Jonides, 1980, 1983; Skelton \& C. W. Eriksen, 1976). In the present experiment, the task was to discriminate between the letters $S$ and $C$ as quickly as possible. One of these target letters was presented with seven other letters (noise) in a circular arrangement around a central fixation point. The diameter of this circle was $1.5^{\circ}$ of visual angle. Four variables were manipulated: (1) the SOA by which a precue preceded display onset; (2) the number of adjacent display locations that were precued on a trial; (3) the presence of response-competitive distractor letters in the display; and (4) the distance, in display positions, of these response-competitive distractors from the precued area in the display.

Extensive prior research has shown that precuing a display location by $50-300 \mathrm{msec}$ before display onset produces from 40 to $120 \mathrm{msec}$ facilitation in choice reaction time, with the magnitude of the facilitation depending upon the number of elements in the display (Colegate et al., 1973; C. W. Eriksen \& Hoffman, 1972, 1973). The SOA values in the present study ranged from -50 to $+200 \mathrm{msec}$, a range presumed to be sufficient for selective processes to be activated.

One of the variables of primary interest was the size of the precued area. One, two, or three adjacent display positions were precued. If the zoom lens, or attentional focus, is enlarged to include all precued locations on each trial, the stimuli within this focus would be processed simultaneously and in parallel. Since the discrimination task would presumably become more difficult as the number of stimuli in the cued area increased, RT would also increase for the target. It is to be noted that the operations of the present experiment are not in themselves sufficient to distinguish between this interpretation and several other alternatives. Instead, an interpretation of an effect due to size of the precued area depends upon converging operations contained in Experiment 2 and results from prior experiments.

A variable of major concern was the distractors. They were of three kinds: (1) neutral noise, consisting of the capital letters $A, N$, and $H$, which have low confusability with the two target letters, S and C; (2) compatible noise, in which the target letter was repeated in one of the display positions other than a cued location; and (3) incompatible noise, in which the other target letter was located in one of the display positions other than a cued location. From prior research (Coles, Gratton, Bashore, C. W. Eriksen, \& Donchin, 1985; B. A. Eriksen \& C. W. Eriksen, 1974; C. W. Eriksen \& B. A. Eriksen, 1979; C. W. Eriksen \& Hoffman, 1973; Grice, Canham, \& Schafer, 1982) we know that if the opposite target letter is processed along with the target, response competition occurs, which appreciably elevates reaction time. From the previous findings we expected that compatible noise (repetition of the target letter in a noncued area) would have little or no effect upon target RT relative to the neutral noise condition. On the other hand, the presence of the opposite target letter in a noncued display location, if processed, should lead to an appreciable increase in $\mathrm{RT}$.

The final variable in this study was the distance between the compatible or incompatible noise letter and the precued area of the display. A compatible or incompatible noise letter was located one, two, or three display positions from the closest precued display position. This distance variable was intended to provide information about a sensitivity gradient around the precued area and to determine whether the focus of attention was cleanly demarked or whether it tapered off into the area of residual processing capacity. This distance variable was also intended to help provide converging evidence for interpreting effects obtained from the manipulation of cue size. Figure 1 shows two sample displays in which three positions are cued. Panel a has an incompatible noise letter two positions away from the cued area; Panel b has a compatible noise letter one position away.

The characteristics of the attentional focus and the appropriateness of the zoom lens analogy were also expected to be revealed in some of the interactions of the four experimental variables. In order to conserve space these specific expectations will be reserved for the Results and Discussion sections.

\section{Method}

Subjects. Four women and 4 men, students at the University of Illinois, served as paid subjects. All were right-handed and had normal or corrected vision (by self-report).

Apparatus and Procedure. Stimuli were presented in a Scientific Prototype three-channel tachistoscope. Viewing was binocu-

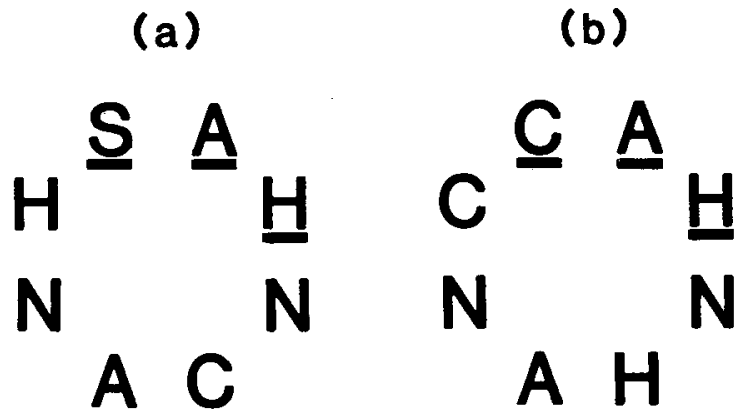

Figure 1. Example of two displays in which three positions are cued. Panel a has an incompatible noise letter two positions away from the cued area, and Panel $b$ has a compatible noise letter one position away. In Panel a the target letter is $\mathbf{S}$, and in Panel $\mathbf{b}$ it is $\mathbf{C}$. 
lar at $122 \mathrm{~cm}$. Luminance was $5 \mathrm{fL}$ as measured by a Spectra Brightness Spotmeter aimed at a patch of the white material used for the stimulus letters.

One hundred twenty-eight circular displays of eight letters were constructed using white Helvetica Medium 24-point capitals (Zipatone dry transfer letters) on black pebbled matte board. The letters were centered about an imaginary circle of $1.5^{\circ}$ of visual angle. Taking the top of the circle as $0^{\circ}$, letters were placed at $22.5^{\circ}$ and at each $45^{\circ}$ increment from that position. Cue displays were constructed of the same materials, using the capital letter I turned horizontally as the cue. This had the effect of underlining the cued positions with the cue located $1 \mathrm{~mm}$ below the bottom of the letter position.

On each trial one, two, or three of the eight positions were cued. The target letters (S and C) appeared equally often in each of the positions cued. Seven distractor conditions were used: neutral noise; a repetition of the target letter one, two, or three positions outside the cued area (compatible noise); or the occurrence of the opposite target letter one, two, or three positions outside the cued area (incompatible noise). All other positions were filled with the letters $A, N$, and $H$, which occurred randomly except that the letters were not repeated in adjacent positions. One hundred twenty-eight stimulus cards thus permitted all the combinations of targets and noise in all positions of the display.

A fixation field consisting of a white dot on a black field remained on except when cue or display fields were on. Cue and letter stimuli were presented for $50 \mathrm{msec}$ each. Cues were presented 50, 100, or $200 \mathrm{msec}$ before the letters (SOA $=50,100$, or $200 \mathrm{msec}$ ) or upon offset of the letters ( $\mathrm{SOA}=-50 \mathrm{msec}$ ).

Trials were blocked by cue size and SOA. Each subject had one practice session, which included 10 trials of each condition. The 13 test sessions each consisted of four blocks of 52 trials with one block of each SOA and one of each cue size with one of the cue sizes repeated. Order of the four blocks within each session was random.

The subject initiated each trial following the verbal instruction "Ready" from the experimenter. The subject was instructed to respond as quickly as possible while keeping errors to a minimum. The subject's response was the movement of a small lever to the right or left with the right hand. Subjects received RT feedback after each trial and were told if they had made an error. Subjects were encouraged to keep error rates below $10 \%$.

\section{Results}

The overall reliability of the data was evaluated in a four-way analysis of variance (SOA, cue size, noise type, and subjects). Since the distance (of noise from cued area) variable did not operate for neutral noise, this variable was treated as one of seven separate levels under noise type. Thus, noise type consisted of neutral noise; compatible noise one, two, and three positions from the nearest cued location; and incompatible noise one, two, and three positions from the nearest cued location. All three of the experimental variables and their interactions were significant beyond the .001 level, with the exception of the triple interaction of SOA $\times$ cue size $\times$ noise type $(p>.50)$. A comparison of compatible and incompatible noise summed over SOA and distance was made. RT with compatible noise was found to be appreciably faster $(p<.001)$. With these highly reliable overall effects in the data established, more specifically directed analyses were carried out.

In Figure 2 we have shown mean RT for target identification under the compatible (Panel a) and the incom- patible (Panel b) noise conditions as a function of SOA and the distance of the compatible or incompatible noise letter from the cued area. Performance under the neutral noise condition is also shown in the figure. As is seen, the effect of precuing the area of the display where the target will appear is a potent variable. Irrespective of whether the display contained compatible, incompatible, or neutral noise, precuing $100 \mathrm{msec}$ before display onset resulted in RT facilitation of from 60 to over $100 \mathrm{msec}$ compared with cuing the target area $50 \mathrm{msec}$ after display onset. The magnitude of the gain in performance is comparable to that obtained in previous studies with precuing (C. W. Eriksen \& Hoffman, 1973; C. W. Eriksen \& Yeh, 1985; Jonides, 1980, 1983). With the possible exception of the -50 -msec SOA value, the compatible noise condition (Figure 2a) was essentially indistinguishable from the neutral noise condition. This outcome is also consistent with previous research findings (B. A. Eriksen \& C. W. Eriksen, 1974; C. W. Eriksen \& Hoffman, 1973; Grice et al., 1982). The lack of effect of compatible noise, as compared with neutral noise, holds for all distances of the compatible noise letter from the cued letter.

The results for incompatible noise are quite different (Figure $2 \mathrm{~b}$ ). Not only does an incompatible noise letter in the display impair RT, compared with neutral noise, but the amount of impairment is directly related to the distance of the incompatible letter from the cued area and is a function of the SOA by which the precue precedes the display. Impairment is greatest if the opposite target noise letter is in the position immediately adjacent to the cued area, and it becomes less if it is two positions removed with an intervening neutral letter. Its effect is further dissipated if two intervening positions occur. For all three distances, as well as for neutral noise, the RT-SOA functions appear to become asymptotic at an SOA value of $100 \mathrm{msec}$, but incompatible noise letters one and two positions removed from the cued area appear to have different asymptotes than do the three-position-removed and neutral noise letters. If the precue precedes a display by $100 \mathrm{msec}$, an incompatible noise letter three positions removed from the cued letter has no more interfering effect than a neutral noise letter, but an incompatible noise letter two positions removed still produces interference, and if the noise letter is immediately adjacent to the cued area even greater interference is produced. The results for positions one and two removed from the cued area are consistent with previous findings of $\mathrm{C}$. W. Eriksen and Hoffman (1973).

The effects shown in Figure 2, along with the effect of cue size, were evaluated separately for the compatible and incompatible noise with ANOVAs for the factors SOA, cue size, distance of noise from the cued area, and subjects. Both analyses contained the neutral noise condition as a fourth level in the distance factor.

In the compatible noise analysis the main effects of cue size and SOA were both quite significant $(p<.0001)$. The cue size $\times$ SOA and cue size $\times$ distance interactions were both significant at or beyond the .01 level. The main 
(a)

\section{Compatible Noise}

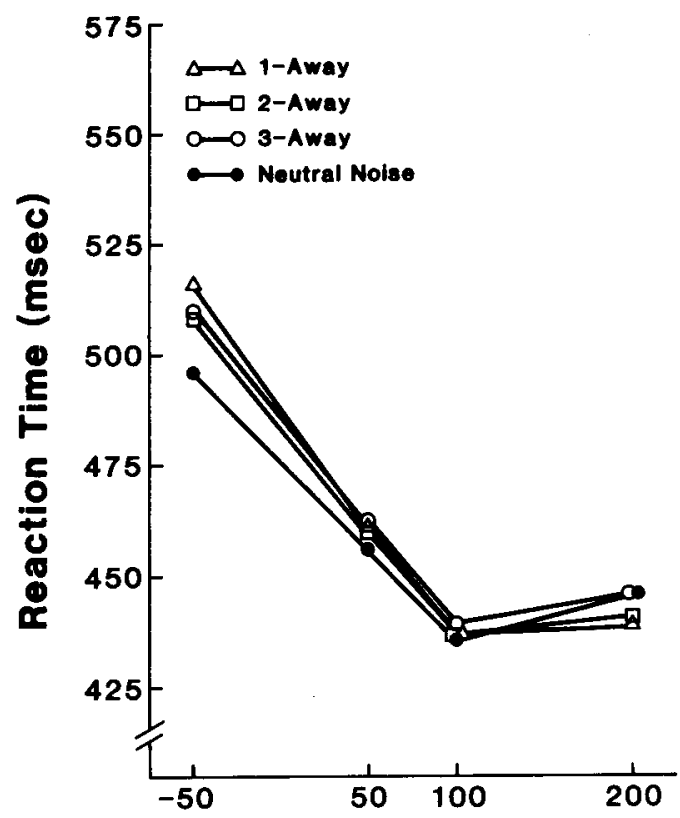

(b)

Incompatible Noise

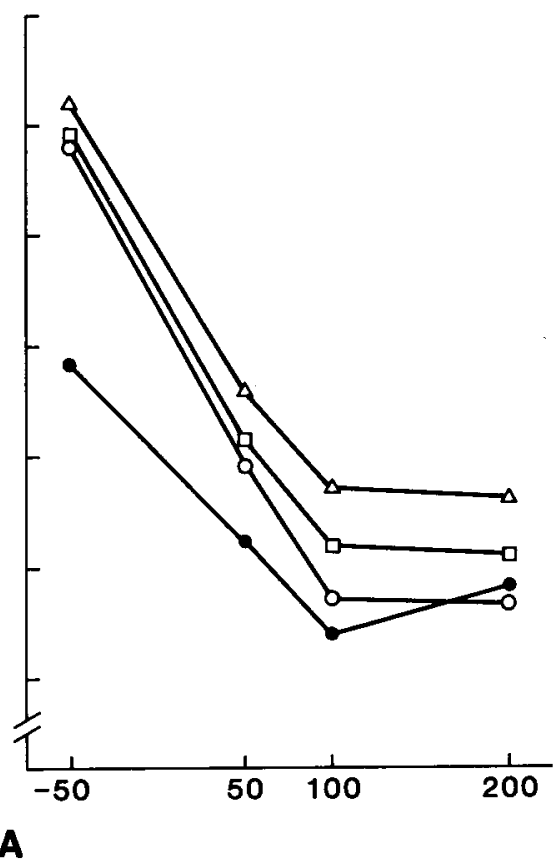

Figure 2. The reaction time-stimulus onset asynchrony functions for different distances of the noise letter from the target letter. The data in Panel a are for the condition in which the noise letter was response compatible and Panel b presents the data for the condition in which the noise letter was incompatible.

effect for distance and the remaining interactions did not approach significance $(p>.10)$. The failure to obtain a significant distance effect suggests that compatible noise did not differ from the neutral noise condition, no matter how few positions separated the compatible noise from the cued letter. However, this distance factor did interact with cue size and the nature of this interaction will be examined below. With this exception, the results of the ANOVA confirm our interpretation of the data as presented in Figure 2a for the compatible noise condition.

The results of the ANOVA on the incompatible noise data also confirm our interpretation of the data in Figure $\mathbf{2 b}$. Here again, cue size and SOA are highly significant $(p<.0001)$, as is the interaction between cue size and SOA $(p<.01)$. In contrast to the compatible noise data, the distance factor is now significant beyond the .0001 level, as is the SOA $\times$ distance interaction. The triple interaction did not approach significance $(p>.5)$. The significant distance effect confirms what is apparent in the figure. The incompatible noise condition differs from the neutral noise condition and, furthermore, the effect of an incompatible noise letter is inversely proportional to its distance from the cued area. The significant SOA $\times$ distance interaction supports our interpretation that the different distances of the incompatible noise from the cued area approach different asymptotes as the SOAs by which the cues precede the display increase.

Although the distance factor for the incompatible noise was significant in the ANOVA, we wished to determine whether the differences between noise one, two, and three positions removed from the cued area were significantly different from each other and from the neutral noise condition. Newman-Keuls post hoc tests were applied to the data collapsed across SOA and cue size for the three positions of incompatible noise and for the neutral noise condition. All six comparisons, of the three distances with each other and with the neutral noise condition, were significant beyond the .05 level.

In Figure 3, mean RT is shown as a function of cue size and distance of the noise letter from the cued area for both compatible (a) and incompatible (b) noise. The data for the neutral noise condition are also plotted in the graphs. The ANOVA reported above for the compatible noise condition failed to show a reliable difference between neutral noise and compatible noise at the three distances. The data in Figure 3a are consistent with this finding. Compatible noise letters one, two, and three positions removed from the cued area appear to vary randomly with respect to the neutral noise condition as cue size varies. The ANOVA had shown a significant interaction between cue size and distance of the compatible noise letter from the cued area. As is seen in the figure, this interaction is mainly attributable to the difference obtained for the position immediately adjacent to the cued area and noise two positions removed for cue size 2 . There appears to be no ready explanation for this effect.

For the incompatible noise, shown in Figure 3b, the effect of distance is consistently ordered across all three 
(a)

Compatible Noise

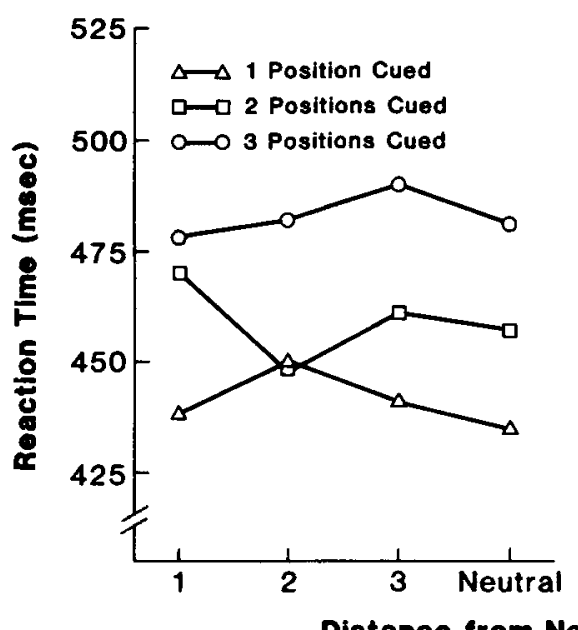

(b)

Incompatible Noise

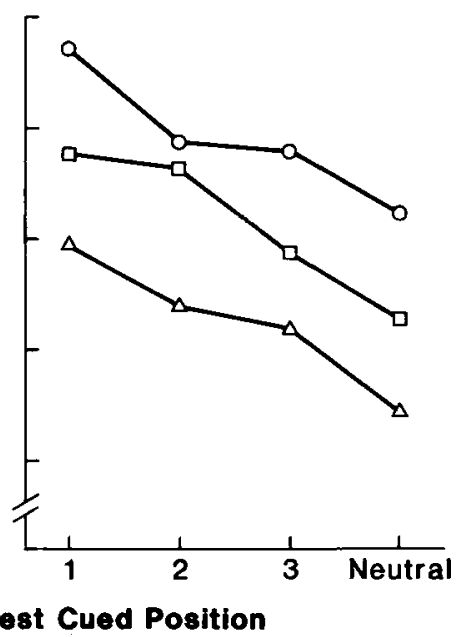

Figure 3. Mean reaction time as a function of the distance of the compatible or incompatible noise letter from the boundary of the cued area. The parameter in the figure is the number of adjacent positions in the display that were cued.

cue sizes, with noise in the adjacent position most effective and that three positions removed least effective. The main finding for the incompatible noise is that the gradient of effectiveness of an incompatible noise letter, which drops off as the distance of that noise letter from the cued area increases, apparently remains essentially constant as the size of the cued area increases. Even when the cued area is enlarged to three positions, an incompatible noise letter three positions removed from the nearest margin of the cued area has almost as much disruptive effect as when the cued area consists only of one position.

The conclusion that the gradient of attentional processing at the border of the focal area is invariant with focus size was tested by computing the slopes of the gradients for each subject. The mean slopes were $-9.3,-11.1$, and $-9.1 \mathrm{msec}$ per position removed from the border of the cued area for cue sizes of one, two, and three positions, respectively. An ANOVA (with factors subjects and cue size) of these slope values resulted in an $F<1$.

In the ANOVAs for both the compatible and the incompatible noise, cue size was found to interact significantly with SOA. Figure 4 presents mean RT as a function of cue size and SOA. Since the overall ANOVA of the data did not show a significant triple interaction between cue size, noise compatibility, and SOA, the data for the compatible, incompatible, and neutral noise conditions have been combined in this figure. It can be seen that the interaction between cue size and SOA is attributable to the three-positions-cued data at an SOA of $200 \mathrm{msec}$. For SOA values of $100 \mathrm{msec}$ or less, the three-positions-cued condition shows the same relationship with SOA as is obtained for the one- and two-positions-cued conditions. The interaction consists of a marked increase in RT for the three-positions data when the SOA was $200 \mathrm{msec}$. We will consider a possible basis for this effect after a discussion of the overall data.

\section{Discussion}

In order to organize and interpret the rather complex results of this experiment, we will use a zoom lens model of attentional focus in the visual field. Since precuing and the SOA by which precues preceded the visual display were the most potent variables in this experiment, we need to make explicit assumptions as to how precuing works. We assume that in the absence of a precue the subject's attentional resources are distributed evenly over the en-

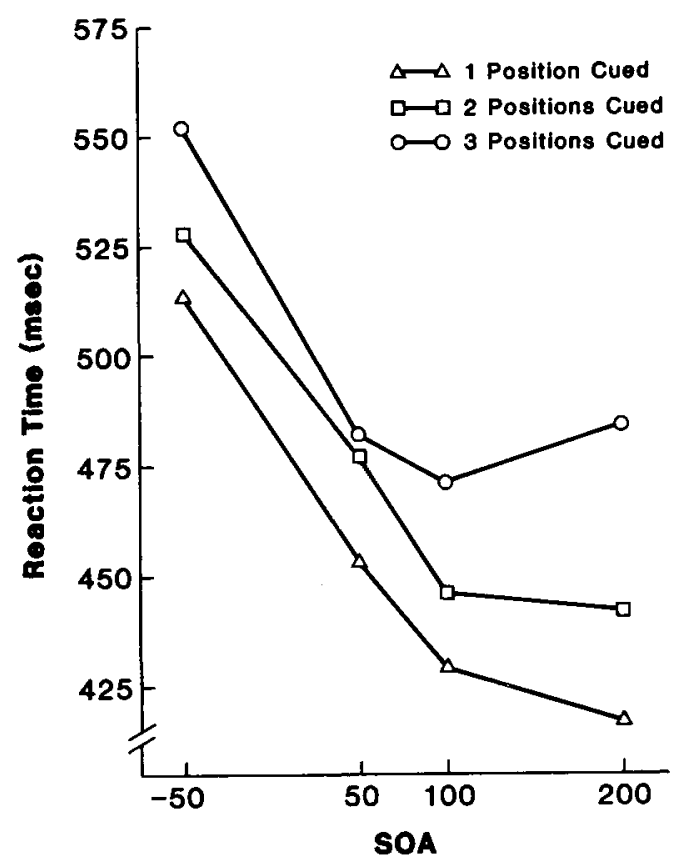

Figure 4. The reaction time-stimulus onset asynchrony functions as a function of the number of adjacent display positions that were cued. 
tire visual display, with parallel processing of all display elements. This assumption has received strong support in the findings of Jonides $(1980,1983)$ and C. W. Eriksen and Yeh (1985). It should be noted that the display in the present experiment was only $1.5^{\circ}$ of visual angle in diameter and was centered well within the fovea. Thus, even in the most distributive mode that we studied, attentional resources were relatively highly focused. In the $-50-\mathrm{msec}$ SOA the entire display appeared first and was present for $50 \mathrm{msec}$ before the appearance of the underlines that designated the possible target positions. Since neutral, compatible, and incompatible noise trials occurred randomly within the same block, subjects could not attain a high level of accuracy on the task without utilizing the underlining cues. For example, on an incompatible noise trial, both target letters appeared in the display and the subject could tell which to respond to only when the underline(s) appeared. In this case, mere parallel processing of all display elements would be inadequate. But since the display was present for $50 \mathrm{msec}$ before the underlining cues occurred, we assume that some processing of all display elements did occur. The alternative target in the display, as incompatible noise, created an opportunity to partially prime its associated response and thus inhibit the correct response. But if attentional resources were uniformly distributed over the entire display, the position of an incompatible noise letter in relation to what would subsequently be the cued positions should have been relatively unimportant.

The data in Figure 2B for the incompatible noise are relevant at this point. As was seen in this figure, the effect of the distance of an incompatible noise letter from the target was less at a -50-msec SOA than it was at SOA values of 50,100, and $200 \mathrm{msec}$. There was, however, still a tendency for noise in a position immediately adjacent to the cued area to produce more interference than noise two and three positions removed, but contrasted with longer positive SOAs, the effect was small and there was no appreciable difference between two and three positions removed.

We assume that when the underlining precues precede the display by positive SOA values, the zoom lens begins to contract the size of the focus field. Some latency must be associated with this change in focus size, because time would be needed to perceive and react to the precues. If the change of attentional focus is actually reflected by a progressive restriction of the attentional field within the visual field, we would expect the effectiveness of incompatible noise letters at different distances from the cued area to vary as a function of SOA. For example, at a 50msec SOA the zoom lens would not have collapsed to as fine a focus as it would have at a 100 - or 200-msec SOA. As a consequence, an incompatible noise letter three positions removed from the cued area may still be within the attentional field of view at a 50 -msec SOA, but by $100 \mathrm{msec}$ the field of view would have collapsed or focused finely enough to exclude a stimulus this distance from the cued area. The data in Figure 2B support this interpretation. At a 50-msec SOA an incompatible noise letter three positions removed from the cued area still has an appreciably greater effect upon reaction time than does the neutral noise condition. By the time the SOA has increased to $100 \mathrm{msec}$, however, noise three positions removed is indistinguishable from the neutral noise, whereas for noise one and two positions removed, even at a 200 msec SOA, there is a significant and differential effect.

This suggests that there are limits to how finely the attentional focus can be drawn. C. W. Eriksen and B. A. Eriksen (1974) found that even when sufficient time was permitted for the subject to focus upon a single letter position, incompatible noise within $1^{\circ}$ of angle of the target position had a significant impairing effect upon target RT. This suggests that the edge of the attentional focus is not a discontinuity, but is, rather, a graded dropoff in processing resources corresponding to William James's conception of a focus, a margin, and a fringe. In the present data, noise one position removed may be interpreted as falling within the margin and two positions removed as in the fringe. With sufficiently long SOAs, noise three positions removed has become part of the background processing and is not distinguished from the neutral noise background.

An alternative to an attentional focus that actually collapses and changes locus in the visual field is a model in which the attentional focus size, or the power of the zoom lens, is set in one large discrete step to correspond to the cued area. If we assume that the latency of this focus adjustment is variable, the effect of SOA would be accounted for in the following manner: The decreasing RT with increasing SOA values would be interpreted as reflecting the increasing probability that, as SOA increased, the latency for a change in focus size occurred before the display came on. Thus, with an SOA of $50 \mathrm{msec}$, performance is based upon two kinds of trials: those in which the latency of the focus adjustment was short enough for the change in focus size to occur and those in which the display occurred before the change in focus had time to occur.

This interpretation, however, would have difficulty accounting for the noise distance effect, particularly as this interacts with SOA. It could be made to work if we assume that focus size has some inaccuracy, so that it overlaps the cued position in one direction on some trials and in the opposite direction on other trials. If we further assume that the focus has a margin and a fringe, we could describe the present results. However, this model would not account for the fact that noise three positions removed becomes indistinguishable from neutral noise at SOAs of $100 \mathrm{msec}$ or greater. A further assumption would be necessary, namely that the accuracy of focus improves when the latency of the focus change is longer.

Size of cued area was found to interact significantly with SOA in the analyses of both the compatible and the incompatible noise. As was seen in Figure 4, the interaction is attributable to the performance of the threepositions-cued condition and an SOA of $200 \mathrm{msec}$. The 
effect of SOA on the one- and two-positions-cued conditions is quite comparable across the SOA range, and through SOA values of $100 \mathrm{msec}$ the three-positions cued data closely correspond, in their functional relationship to SOA, with the data of the other size cued areas.

An increase in RT for three-position data at a 200-msec SOA was not anticipated. However, this increase is characteristic of both compatible and incompatible noise at all three distances, as well as of the neutral noise condition [the four-way interaction of cue size, SOA, compatibility, and distance did not approach significance $(p>.30)]$. A possible explanation for the effect may lie in the size of the cued area relative to the total display size. When three adjacent positions are cued, nearly one half of the circular display is involved in the cued area. If attentional focus has essentially a circular shape, then an attempt to focus on three adjacent positions would encompass almost the entire display. From the one- and twopositions-cued data it is apparent that RT is becoming asymptotic at an SOA value of $100 \mathrm{msec}$. We suggest that with three positions cued, the 200-msec SOA gives the subject the opportunity to change his/her strategy on a certain proportion of trials. Upon seeing the relatively large area of focus relative to the total display size, subjects may either be reverting to a parallel processing mode or continuing to focus down to only one position in the cued area on some trials. When the size of the cued area is very large relative to the total display size, a transition point may be reached at which it is nearly as efficient to process the entire display in parallel as it is to focus on such a large proportion of the display (Experiment 2 tested this proposition.)

As the number of precued positions increased in the display, RT increased. When the precuing preceded the display by $100 \mathrm{msec}$, approximately $15 \mathrm{msec}$ more were required for target identification when two display positions were precued than when only one position was precued. Increasing the cued area to three adjacent positions resulted in another $15-\mathrm{msec}$ increase in RT. There are at least three possible bases for this increase in RT as the precued area increased. One possibility is that the subjects were not distributing their attentional resources over all precued display positions, but instead were using a highly focalized approach and examining each precued position in a serial self-terminating search. A second factor is that the discriminative task for the subject changed as the number of precued positions increased. A third possibility that is consistent with the zoom lens analogy is that a limited amount of processing resources had to be distributed over a greater area in the visual field as the number of cued locations increased, with a resulting decrease in processing efficiency.

Most critical for the zoom lens analogy is the possibility that the increase in RT with increasing size of precued area reflects a serial search, position by position, of the cued locations. If subjects focused attention on only one cued location at a time, then, as the number of cued locations increased, the probability that they had selected the correct location would decrease, leading to an increase in RT with an increase in cued area. When they focused on the incorrect location, subjects would have at least two alternative strategies: they could use either a selfterminating or an exhaustive serial search of the remaining locations for the target, or they could revert to a parallel mode of processing and process all of the display elements. Jonides (1980) found that when a precue was invalid, subjects reverted to parallel search of the remaining display positions. He was able to convincingly rule out both the self-terminating and exhaustive serial searches. C. W. Eriksen and Yeh (1985), in a quite similar study, found that when a primary and a secondary position were cued, subjects responded to invalid primary cues by serially searching first the secondary cued area and then the remaining two possible target locations. Their experiment is more comparable than that of Jonides to the present experiment: if the target was not found in the first position focused upon, subjects would search other cued areas rather than search the entire display in parallel.

Several considerations strongly suggest that subjects in the present experiment were allocating attentional resources to the entire cued area simultaneously, rather than concentrating on only one cued position at a time. Foremost is the finding of Jonides (1983) and of C. W. Eriksen and Yeh (1985) that there is an appreciable cost if the subject has focused attention in response to an invalid cue. C. W. Eriksen and Yeh found this cost to be an increase of 60-70 msec over the RT obtained when subjects processed the display in parallel. Furthermore, C. W. Eriksen and Yeh showed that the cost was primarily attributable to the time required for subjects to process the noise letter in the invalid cued location to a level at which it could be determined that the letter was not a target.

The strongest evidence that the subjects did not serially search the cued locations in the present experiment is the finding that RT increased by only about $30 \mathrm{msec}$ as the cued area increased from one to three positions. If subjects focused on only one cued position, then this position would always have been valid when only one position was precued. When two positions were precued, on about half of the trials subjects would have had to process a neutral letter to a level sufficient to determine that it was not a target, and then shift their attentional focus to the other cued location. Given the $60-70 \mathrm{msec}$ that this processing has been found to require, RT at the 100 msec SOA should have been about $35 \mathrm{msec}$ longer for two positions cued than for one. The actual difference in RT was less than half this value. Similar logic and computations for the three-positions-cued condition lead to a predicted difference between the one- and three-positionscued conditions of about $65 \mathrm{msec}$, which contrasts with the obtained value of $30 \mathrm{msec}$.

Additional evidence that the subjects were distributing attention over the entire precued area is found in the gradients obtained for an incompatible noise letter located one, two, or three positions removed from the precued 
locations. As was seen in Figure 3, the disruptive effect of incompatible noise progressively decreased as the noise was located one, two, or three positions from the edge of the nearest precued location. This gradient was obtained for all three sizes of precued areas. If, instead of using an attentional focus that encompassed all precued locations, the subjects focused attention on only one of the precued locations at a time and serially searched them until the target was located, then incompatible noise one position removed would always have been immediately adjacent to the first position focused upon when only one position was precued. With two positions precued, noise one position removed would have been adjacent to the first position focused upon on only half the trials, and with three positions cued, on only one third. Therefore, when three positions were precued, the disruptive effect of the incompatible noise letter one position removed, averaged over trials, should have been comparable to the effect obtained for noise two positions removed when only one position was precued. In fact, however, noise one position removed produced as much disruptive effect, relative to the neutral noise condition, when three positions were cued as it did when only one position was cued. If RT for target identification with incompatible noise one position removed is compared with $\mathrm{RT}$ for the neutral noise condition for each size of precued area, the data in Figure 3 show the following: With one position precued, noise one position removed increased RT by $39 \mathrm{msec}$ over RT for the neutral noise condition; with two positions precued, the increase was $37 \mathrm{msec}$; with three positions precued, the increase was $38 \mathrm{msec}$. The close correspondence of these times strongly suggests that the amount of processing given the noise letter is determined by its proximity to the attentional focus and not to the actual position of the target letter. This correspondence is not consistent with a position-by-position serial search of the precued positions.

On the basis of the above considerations, we conclude that the present data are most consistent with the conclusion that the attentional resources are essentially uniformly distributed over the entire precued area. The increase in RT with increases in size of the precued area would then be attributable to a change in the discriminative difficulty of the task with increasing cued area size, and possibly to a watering down of the processing resources as they are distributed over a greater area. There is ample evidence that the discriminative requirements of the task change as the size of the cued area increases (C. W. Eriksen \& Spencer, 1969; Lappin \& Uttal, 1976). With only one position precued, the subject's decision regarding the letter in this location would be in terms of whether it looked more like an $S$ or a C. But with two or more precued positions, there would be a greater opportunity for misidentifications to occur. In order to maintain the same accuracy criterion, the subject may need to permit further development of the percept. This, in turn, would increase his/her RT.
Confounded with this change in discrimination difficulty is the possibility that as the attentional focus is distributed over a greater area of the visual field, the density of processing resources per unit area is decreased. This would be consistent with the zoom lens analogy, but would hold only if the subject did not have additional attentional resources to deploy on the task as the size of the precued area became greater. In the introduction, we proposed a principle of optimal allocation of attentional resources. This principle recognizes that the level of task performance is not due solely to the amount of attentional resources directed to the task. Level of performance is significantly determined by sensory factors, motor factors, and processing mechanisms other than attention. In other words, there is an optimal level of attentional resources for a given task and further attentional resources devoted to the task will not result in an improvement in performance. Subjects have learned from experience to make good judgments as to the optimum amount of attention that will benefit a given task. Thus, when only one position is precued in the display, subjects devote less attentional resources to the task than they do when three positions are precued. They perceive the latter condition as being more difficult and more apt to benefit from a greater investment of resources. If this principle is valid, it will be extremely difficult to demonstrate experimentally that processing efficiency decreases with increased size of the focus due to a thinning out of resources in the focus field.

One finding in the present data strongly suggests that subjects draw on additional attentional resources as the size of the cued area increases. The data in Figure 3B shows that the gradients reflecting the disruptive effect of an incompatible noise letter one, two, or three positions removed from the edge of the focus area were independent of the number of precued locations. All three gradients had essentially the same slope. This finding is inconsistent with a model in which a constant supply of resources is distributed over an increasingly larger area. Were this the case, the ratio of processing resources to residual resources in the focus area would decrease as the size of the focus area increased, resulting in a change in the gradient on the border of the focus. Instead, the result is consistent with an interpretation that subjects devoted more attentional resources to the task as the size of the focused area increased. If this interpretation is accepted, then the increase in RT with increasing size of cued area would be attributable to the changing nature of the discrimination as more possible targets are precued or underlined.

\section{EXPERIMENT 2}

Our objectives in this experiment were threefold. First, we wished to determine whether, as the ratio of the cued area in the circular display increased relative to the total display area, there was a point at which the subject ceased to focus attention on the cued area and instead processed 
the entire display in parallel. The data from Experiment 1 given in Figure 4 show that overall, RT increased as the size of the cued area increased, and that the effect of the SOA by which the precue preceded the display was highly similar for the one- and two-positions-cued conditions. When three positions were cued, the effect of SOA was comparable to that obtained when one and two positions were cued, up to an SOA of $100 \mathrm{msec}$. But when the SOA was $200 \mathrm{msec}$, RT for the three-positions-cued condition increased reliably, whereas for the one- and two-positionscued conditions the function decreased or was asymptotic. We speculate that this aberrant effect could be attributed to the subjects' changing from a focus mode to a distributive mode on a certain proportion of the trials. Alternatively, they may have continued focusing down to only one of the three cued positions on a small proportion of the trials. Experiment 2 was designed to investigate this effect: we precued four adjacent positions (half the display) as well as all eight display positions.

The second purpose of this experiment was to provide a critical test of our interpretation that attentional resources were distributed over the cued positions. In the preceding experiment, incompatible noise letters were located one, two, or three positions removed from the edge of the cued area. Thus, as the size of the cued area increased, the distance of a noise letter one position removed varied in its distance from the target. With two positions cued, on half of the trials a noise letter so located would be one position away from the actual target, and on the other half of the trials it would be two positions removed. In the present experiment we varied the distance of incompatible noise letters from the actual target independently of their location within or outside the cued area. Our interpretation that attentional resources are uniformly distributed within the cued area critically depends upon finding that a noise letter one position removed from the target has a greater effect if it also falls within, rather than outside, the cued area. Failure to obtain such an effect would make our interpretation of uniform distribution of attentional resources in the cued area untenable. However, finding the effect would not necessarily rule out other possible interpretations.

The third purpose of the experiment was to provide a check on our assumption that in the absence of precues the subject processes the entire display in parallel, or that attentional resources are distributed evenly over the display area. This assumption has received strong support in prior research (C. W. Eriksen \& Yeh, 1985; Jonides, $1980,1983)$, but the use of an incompatible noise letter in the display in the present experiments provides a particularly sensitive test.

\section{Design and Rationale}

The procedure and stimuli were quite similar to those employed in Experiment 1. The eight letters in a display were equally spaced along the circumference of an imaginary circle $1.5^{\circ}$ in diameter. One, two, four, or all eight display positions were precued. Because SOA was not a primary concern, only two values were used, $50 \mathrm{msec}$ and $175 \mathrm{msec}$. The displays consisted of either a single target letter and seven neutral noise letters or a target letter, an incompatible noise letter, and six neutral letters. When an incompatible noise letter occurred in the display, it was either one or two positions removed from the target-letter location. Thus, on some trials the incompatible noise letter was within the cued area in the display, and on other trials it was outside the precued area. Because the incompatible noise letter occasionally fell within the precued area, it was not possible to use the other target letter as incompatible noise, because the subject would not know which of the two letters was actually the designated target on the trial. To get around this problem we selected two letters, each of which had high feature similarity to one or the other target letter. The two target letters were $\mathrm{N}$ and $\mathrm{Y}$, and the confusable incompatible noise letters were $H$ and $V$. The neutral noise letters, $O$, $\mathrm{C}$, and S, had low feature similarity to the target letters and the incompatible noise letters. We knew on the basis of prior research (B. A. Eriksen \& C. W. Eriksen, 1974; C. W. Eriksen \& B. A. Eriksen, 1979; Yeh \& C. W. Eriksen, 1984) that the feature similarity between $Y$ and $\mathrm{V}$ and between $\mathrm{N}$ and $\mathrm{H}$ would elicit competing responses, which would be enhanced by the neutral noise consisting of letters with curved features.

We anticipated that when all eight display positions were precued the subject would process all display elements in parallel, that is, distribute attentional resources evenly throughout the display. If this did occur, we would expect that RT to target letters would be significantly longer than when the subject focused attention on a single letter or subset of the display. In other words, the target letter would not benefit from increased processing resources. Furthermore, the effect of an incompatible noise letter should be enhanced and its distance from a target letter should be immaterial. The incompatible noise letter would receive equal processing resources with the target letter, which should enhance the response-competitive effect.

Precuing all eight display positions also provided an anchor for determining how large a proportion of the display positions could be precued before the subject ceased to use the precue and began to process the entire display in parallel. On the basis of the results obtained in Experiment 1 , at the 200-msec SOA with three positions cued, we anticipated that this would occur with four positions precued, because this constituted half of the display.

If subjects processed the entire display in parallel when four positions were precued, then the two-positionsprecued condition would provide our only test of whether an incompatible noise letter is more effective when it is within a cued area than when it is outside the cued area (holding distance from the target letter constant). Thus, the two-positions-cued condition provides a critical test of whether processing resources are uniformly distributed over the entire precued area. If they are, we should find that an incompatible noise letter one position removed from the target letter is more effective in disrupting RT 
if it lies in a cued portion of the display than if it is one position removed from the target area but in a noncued position.

\section{Method}

Subjects. Three women and 3 men, students at the University of Illinois, served as paid subjects. Each served in seven sessions, of which the first was practice. All were right-handed and had normal or corrected vision (by self-report).

Apparatus, Stimuli, and Procedure. Apparatus and viewing conditions were the same as in Experiment 1. For the present experiment, 80 circular displays of eight letters were constructed of the same materials employed in Experiment 1. A target display was made with each target ( $N$ or $\mathrm{Y}$ ) in each of the eight positions. For each of these 16 target conditions, five different kinds of noise displays were made: (1) neutral noise, consisting of the letters $\mathrm{O}, \mathrm{C}$, and S; (2) an incompatible noise letter one position clockwise from the target; (3) an incompatible noise letter two positions clockwise from the target; (4) an incompatible noise letter one position counterclockwise from the target; and (5) an incompatible noise letter two positions counterclockwise from the target. When the target was $\mathbf{N}$, the distractor was $\mathbf{V}$ (chosen because of feature overlap with the alternate target $Y$ ). When the target was $Y$, the distractor was $H$. When the incompatible noise letter appeared in the display, the remaining display positions were filled with repetitions of the letters $\mathrm{O}, \mathrm{C}$, and $\mathrm{S}$. These were arranged randomly except that each letter appeared twice in each display position (in the neutral noise condition one of these letters appeared three times), and the same letter could not occupy adjacent display positions.

Trials were blocked by SOA and cue size. Two SOAs were used, $50 \mathrm{msec}$ and $175 \mathrm{msec}$. For the single-letter-cued condition, each of the eight positions was cued equally often. The letter cued was always the target letter. Distractors could be absent, one position away in either direction (one-out), or two positions away in either direction (two-out).

For the two-letters-cued condition, the two letters at the top, bottom, right, or left of the display were cued. The incompatible noise letter could be absent (neutral noise), one position away from the target and inside the cued area (one-in), one position away and outside the cued area (one-out), or two positions away and outside (two-out).

For the four-letters-cued condition, the four letters were in the upper half, lower half, left half, or right half of the display. In these conditions incompatible noise could be absent (neutral noise), one position away and inside the cued area (one-in), one position away and outside the cued area (one-out), two positions away and inside, or two positions away and outside (two-in and two-out).

For the eight-letters-cued condition, noise was absent (neutral noise) or one or two positions away from the target (one-in and two-in).

Each condition (SOA $\times$ cue size) required 160 trials, broken into blocks of 50, 50, and 60 trials. Each of the six test sessions comprised eight blocks of trials: one of each cue size and two of each SOA. The order of blocks across sessions was random within these constraints, as was the order of the eight blocks within each session. The practice session consisted of 20 trials of each condition. The first four blocks of the practice session were one, two, four, and eight letters cued with a 175-msec SOA: the next four blocks were one, two, four, and eight letters cued with a 50-msec SOA.

\section{Results and Discussion}

The data were first analyzed in a four-way analysis of variance (SOA, cue size, location, and subjects). There were three levels of the location variable: incompatible noise one position removed from the target, incompatible noise two positions removed from the target, and neu- tral noise. In this analysis the location of the incompatible noise, within or outside the cued area, was ignored. The main effects of all three of the experimental variables were significant $(p<.01)$. The only significant interaction $(p<.01)$ was cue size $\times$ location of incompatible noise. The interaction of SOA $\times$ cue size approached significance $(p<.05)$.

Figure 5 shows mean RT as a function of size of cued area for the neutral noise condition and for incompatible noise one and two positions away from the target letter. The figure shows that when four adjacent positions were precued (one half of the display), performance closely approached that for eight positions cued (effectively no precue at all). This finding supports our suggestion that the atypical performance with three positions cued at a 200-msec SOA in Experiment 1 was attributable to the existence of a transition point at which subjects on a certain proportion of trials reverted to parallel processing of the entire display. While the evidence is certainly not unequivocal, it does suggest that the attentional focus may be circular or oval in shape.

Because precuing all eight positions in the display provides no information as to target location, we have assumed that the subjects used a parallel processing approach to the entire display area, that is, that their attentional focus encompassed all eight positions in the display. This assumption is supported by two characteristics of the data in Figure 5. First, the effectiveness of an incompatible noise letter in disrupting RT was much greater for the eight-letters-precued condition than for one or two letters cued. This would be expected if the subjects were processing all items in the display in parallel.

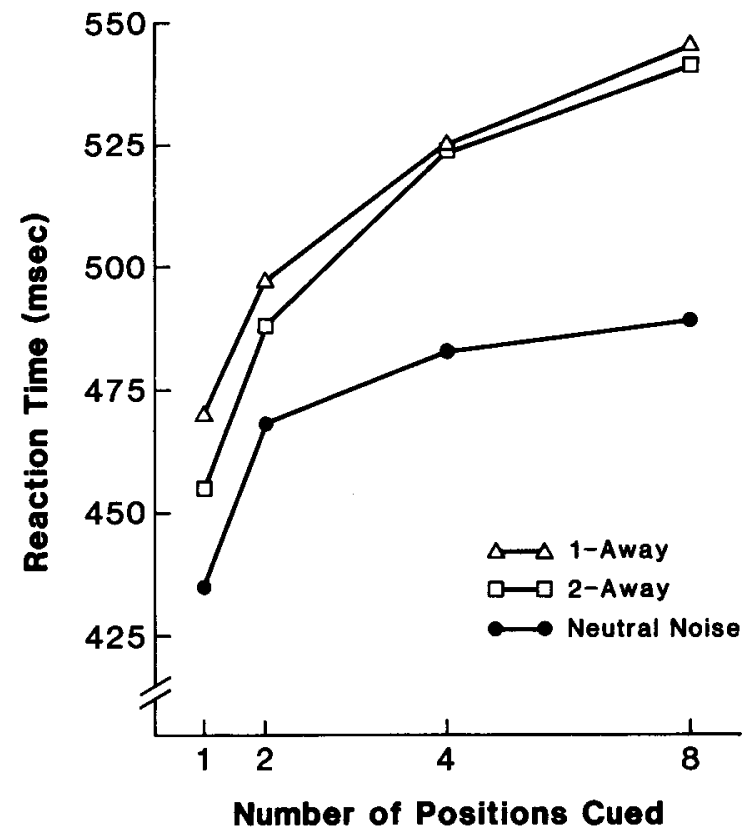

Figure 5. Mean reaction time as a function of the number of adjacent display positions that were precued. The parameter in the figure is the distance in display positions of an incompatible noise letter from the target. 
Under these circumstances, the same amount of processing resources would be devoted to the incompatible noise letter and to the target letter. Consequently, the features of the incompatible noise letter would have a relatively greater opportunity to activate or prime the competing response (Eriksen \& Schultz, 1979). With the more finely focused attentional field that occurs when only one or two positions are cued, the target is processed more rapidly than the noise letter, and there is less priming of the competing response.

A second characteristic of the data commensurate with this interpretation is the lack of effect for location of the incompatible noise letter when all eight positions were precued. If the entire display were processed in parallel, or, alternatively, if processing capacity were evenly allocated for all eight positions, then the proximity of the incompatible noise letter to the target letter would be a matter of indifference.

In contrast, location of the incompatible noise letter was a significant variable when only one or two positions were precued. An incompatible noise letter one position from the target produced significantly $(p<.05)$ more interference in RT than one located two positions from the target. The effect of incompatible noise and its location when four positions were precued is quite comparable to that obtained when all eight positions were precued. This is consistent with our interpretation that when half of the display was precued, subjects predominantly concentrated their attentional resources over the entire display area rather than attempting to focus on only half of the circular display.

In Figure 6 we have analyzed the data for the one- and two-positions-cued conditions in more detail. Figure 6a shows mean RT as a function of SOA for incompatible noise one and two positions removed from the target, as well as for neutral noise in the one-position-cued condition. Figure $6 \mathrm{~b}$ shows corresponding data for the twopositions-cued condition.

Separate ANOVAs were carried out on these data. For the one-position-cued condition, the effects of SOA and location were both significant $(p<.01)$, but the interaction term did not approach significance. Pairwise comparisons showed that the one-position-cued condition differed significantly from the two-positions-cued condition $(p<.05)$ and that both differed significantly from the neutral noise condition $(p<.05)$. With two positions precued, the SOA did not reach significance $(p>.10)$, nor did the interaction, but noise position was again a significant effect $(p<.001)$. Pairwise comparisons showed that noise one position away from the target and inside the precued area not only differed significantly from neutral noise but was also significantly different from noise one position from the target but outside the precued area $(p<.05)$. Noise one position from the target and inside the cued area also differed significantly from noise two positions from the target and outside the cued area. However, noise one and two positions outside the precued area did not differ significantly from neutral noise. (a)

1 Position Cued

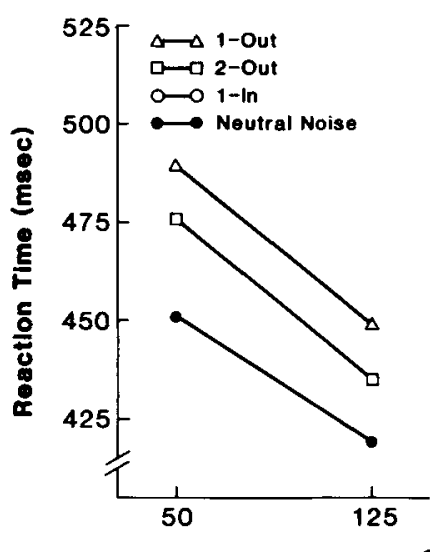

(b)

2 Positions Cued

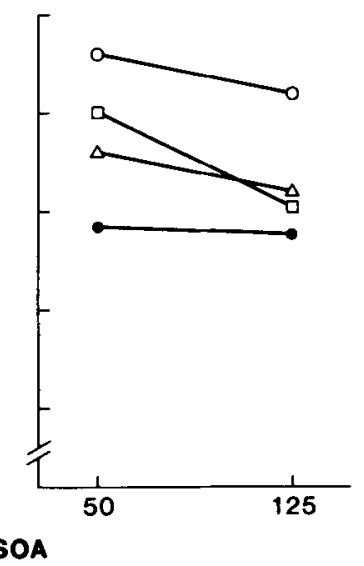

Figure 6. The reaction time-stimulus onset asynchrony functions for differing locations of an incompatible noise letter relative to the target. The data in Panel a are for the condition in which only one display position was precued. Panel b presents the data for the condition in which two adjacent positions were precued.

These data from the two-positions-precued condition provide a critical test of our hypothesis that attentional resources are evenly distributed and concentrated over the precued area. This hypothesis would require that an incompatible noise letter inside the precued area exert a more disruptive influence upon RT than the same incompatible noise letter outside the cued area, even though its distance from the target was the same. As the results of the analysis of the two-positions-precued data show, this effect was indeed obtained.

Pair-wise comparisons for the different-sized precued areas show that the one-position-precued condition differs significantly $(p<.05)$ from the two-, four-, and eightpositions-precued conditions. Similarly, the two-positionsprecued condition differed significantly from the four- and eight-positions-precued conditions. There was, however, no significant difference between the latter two conditions.

In summary, the results of Experiment 2 are, in the main, in keeping with our expectations, and support the assumptions we made in interpreting the data of Experiment 1 . The evidence strongly suggests that in the absence of effective precues, subjects process the entire display in parallel. In other words, their attentional focus is the size of the eight-letter circular display. This is supported by the lack of effect of location of an incompatible noise letter and by the relatively greater effectiveness of this noise letter, irrespective of its distance from the target. The comparability of performance for the four-positionsprecued condition and the all-eight-positions-precued condition supports the conclusion that when half of the display is precued, subjects predominantly use the same approach as if the whole display were precued. This suggests that the anomaly found in Experiment 1 when three positions were cued at a 200 -msec SOA was attributable to the subjects' reverting to a parallel processing approach to the entire display on a small proportion of the trials, 
which the long SOA permitted them to do. Furthermore, the critical prediction of the zoom lens model that an incompatible noise letter would be more effective in disrupting RT if it were within the cued area than if it were outside (holding distance from the target letter constant) was clearly supported. This finding does not rule out alternative interpretations of the data, but failure to obtain it would have required rejection of the zoom lens model.

There was one discrepancy between the results of Experiment 2 and those of Experiment 1. In Experiment 1, noise locations one, two, and three positions from the margin of the cued area differed significantly from each other in terms of the disruptive effect upon RT. In Experiment 2 , significant differences between noise locations removed one and two positions from the cued area were obtained only for the one-position-precued condition. The only other test of distance from the cued area in the present experiment was for the two-positions-precued condition, in which incompatible noise letters one and two positions from the edge of the precued area did not differ significantly from each other, nor did either differ significantly from the neutral noise condition. However, the direction of the differences was in correspondence with the data from Experiment 1, and the failure to obtain significance may be attributable to the smaller numbers of trials and subjects employed in Experiment 2, as well as to lesser effectiveness of the incompatible noise letter. In Experiment 1 , the incompatible noise letter was the alternative target, whereas in the present experiment, a nontarget letter with high feature overlap (in terms of angles and straight lines) was used for the incompatible noise.

\section{SUMMARY}

The results of these two experiments provide suggestive, if not definitive, answers to the three questions we addressed and are well described by a zoom lens model. The size of the visual attentional focus can be manipulated by precuing, and this area of attentional focus is characterized by essentially even distribution of processing resources. This conclusion was supported in the present data by the disrupting effect on RT of incompatible noise letters within and outside the boundaries of the precued areas. It is also supported by converging evidence from other experiments. The increase in RT as the size of the cued area increased was not sufficient to allow for the processing of noise letters in invalid cued locations, which would be required if subjects were performing a serial search of the cued area (C. W. Eriksen \& Yeh, 1985). The results confirm the findings of other investigators (Jonides, 1983; LaBerge, 1983) that the attentional field can vary in size depending upon the task.

The zoom lens analogy also suggests that as the size of the attentional field increases, the density of processing resources within the field decreases. Indeed, in the present experiments, RT to targets did increase as the number of cued positions increased, indicating a possible reduction in resources for processing the individual stimuli in the cued area. However, part of the increase in RT with an increase in cued positions must be attributed to a change in the discriminative difficulty of the task. The cued area may be thought of as a subdisplay within a larger display, and, as its size increases, RT for target identification also increases, due in part to the greater opportunity for confusions. A reduction of attentional resources allotted to each cued position would occur only if the subject had no additional attentional resources to devote to the task as it became more difficult (that is, as the number of cued locations increased). The analyses of processing gradients bordering the attentional field strongly suggest that within the focus sizes we investigated, the subjects were able to draw upon additional attentional resources to compensate for an increase in focus size.

The data are quite clear in showing a processing gradient on the borders of the attentional focus. The disruptive effect of incompatible noise letters decreased progressively as the noise letter was located from $.5^{\circ}$ to $1.5^{\circ}$ of angle from the edge of the cued area. The slopes of these gradients were essentially the same irrespective of whether the cued area was one, two, or three positions.

The data also show that as attentional focus is directed to a different location in the visual field, the precision of the focus in this new location improves over time. With the present experimental tasks, the RT-SOA functions appeared to be asymptotic at SOA values of $100 \mathrm{msec}$. At SOA values of less than $100 \mathrm{msec}$, incompatible noise disrupted RT even when it was located nearly $1.5^{\circ}$ from the edge of the cued area. However, by the time the functions had become asymptotic, incompatible noise this far removed from the border of the cued area had no more effect than neutral noise. Even at asymptotic RT-SOA values, however, incompatible noise within about $1^{\circ}$ of visual angle of the border of the attentional focus still produced disruptive effects.

\section{REFERENCES}

BECK, J., \& AMBLER, B. (1973). The effects of concentrated and distributed attention on peripheral acuity. Perception \& Psychophysics, 14, 225-230.

Colfgate, R., Hoffman, J. E., \& Eriksen, C. W. (1973). Selective encoding from multielement visual displays. Perception \& Psychophysics, 14, 217-224.

Coles, M. G. H., Gratton, G., Bashore, T. R., Eriksen, C. W., * Donchin, E. (1985). A psychophysiological investigation of the continuous flow model of human information processing. Journal of Experimental Psychology: Human Perception \& Performance, 11, 529-553.

DiLoLLo, V. (1977). Temporal characteristics of iconic memory. $\mathrm{Na}$ ture, 267, 241-243.

EGETH, H. (1977). Attention and preattention. In G. H. Bower (Ed.), The psychology of learning and motivation, 11, 277-320.

ERIKSEN, B. A., \& ERIKSEN, C. W. (1974). Effects of noise letters on the identification of a target letter in a nonsearch task. Perception \& Psychophysics, 16, 143-149.

Eriksen, C. W., \& Colegate, R. L. (1970). Selective attention and serial processing in briefly presented visual displays. Perception \& Psychophysics, 10, 321-326.

Eriksen, C. W., \& Coluins, J. F. (1969). Temporal course of selective attention. Journal of Experimental Psychology, 80, 254-261.

ERIKSEN, C. W., \& ERIKSEN, B. A. (1979). Target redundancy in visual 
search: Do repetitions of the target within the display impair processing? Perception \& Psychophysics, 26, 195-205.

ERIKSEN, C. W., \& HofFMAN, J. E. (1972). Temporal and spatial characteristics of selective encoding from visual displays. Perception \& Psychophysics, 12, 201-204.

ERIKSEN, C. W., \& HoffMan, J. E. (1973). The extent of processing of noise elements during selective coding from visual displays. Perception \& Psychophysics, 14, 155-160.

ERIKSEN, C. W., \& Hoffman, J. E. (1974). Selective attention: Noise suppression or signal enhancement? Bulletin of the Psychonomic Society, 4, 587-589.

Eriksen, C. W., \& Rohrbaugh, J. W. (1970). Some factors determining efficiency of selective attention. The American Journal of Psychology, 83, 330-342.

ERIKSEN, C. W., \& SChULTZ, D. W. (1979). Information processing in visual search: A continuous flow conception and experimental results. Perception \& Psychophysics, 25, 249-263.

ERIKSEN, C. W., \& SPENCER, T. (1969). Rate of information processing in visual perception: Some results and methodological considerations. Journal of Experimental Psychology Monograph, 79(2, Pt. 2), 1-16.

ERIKSEN, C. W., \& YEH, Y. (1985). Allocation of attention in the visual field. Joumal of Experimental Psychology: Human Perception \& Performance, 11, 583-597.

Grice, G. R ., Canham, L., Schafer, C. (1982). Development of associative and perceptual interference. Perception \& Psychophysics, 32, 375-387.

HoFrman, J. E. (1975). Hierarchical stages in the processing of visual information. Perception \& Psychophysics, 18, 348-354.

HoFFMAN, J. E. (1978). Search through a sequentially presented visual display. Perception \& Psychophysics, 23, 1-11.

Hoffman, J. E. (1979). A two-stage model of visual search. Perception \& Psychophysics, 25, 319-327.

JAMEs, W. (1950). The principles of psychology. New York: Dover. (Original work published 1890 )

JoNIDES, J. (1980). Toward a model of the mind's eye. Canadian Journal of Psychology, 34, 103-112.

JoNIDES, J. (1983). Further toward a model of the mind's eye's movement. Bulletin of the Psychonomic Society, 21, 247-250.

Kahneman, D. (1973). Attention and effort. Englewood Cliffs, NJ: Prentice-Hall.

Keren, G., \&kelton, J. (1976). On selecting between theories of selective attention. Perception \& Psychophysics, 20, 85-86.
KINCHLA, R. A. (1974). Detecting target elements in multielement arrays: A confusability model. Perception \& Psychophysics, 15, 149-158.

LABERGE, D. (1983). Spatial extent of attention to letters in words. Journal of Experimental Psychology: Human Perception \& Performance, 9, 371-379.

LAPPIN, J. S., \& UTTAL, W. R. (1976). Does prior knowledge facilitate the detection of visual targets in random noise? Perception \& Psychophysics, 20, 367-374.

Posner, M. I., SNyder, R. R., \& Davidson, D. J. (1980). Attention and the detection of signals. Journal of Experimental Psychology: General, 109, 160-174.

Prinzmetal, W., \& Banks, W. P. (1983). Perceptual capacity limits in visual detection and search. Bulletin of the Psychonomic Society, 21, 263-266.

SHAW, M. L. (1978). A capacity allocation model for reaction time. Journal of Experimental Psychology: Human Perception \& Performance, 4, 586-598.

Shaw, M. L., \& Shaw, P. (1977). Optimal allocation of cognitive resources to spatial locations. Journal of Experimental Psychology: Human Perception \& Performance, 3, 201-211.

SHIFFrin, R. M., \& GARDNER, G. T. (1972). Visual processing capacity and attentional control. Journal of Experimental Psychology, 93, $72-82$.

SHIFFrIN, R. M., \& GeISLER, W. S. (1973). Visual recognition in a theory of information processing. In R. Solso (Ed.), The Loyola Symposium: Contemporary issues in cognitive psychology. Washington, DC: Halsted Press.

ShIFfrin, R. M., McKay, D. P., \& ShafFer, W. D. (1976). Attending to forty-nine spatial positions at once. Journal of Experimental Psychology: Human Perception \& Performance, 2, 14-22.

SKelton, J. M., E ERIKSEN, C. W. (1976). Spatial characteristics of selective attention in letter matching. Bulletin of the Psychonomic Society, 7, 136-138.

Wickens, C. D. (1978). The effects of divided attention on information processing in manual tracking. Journal of Experimental Psychology, 105, 1-17.

YEH, Y., ERIKSEN, C. W. (1984). Name codes and features in the discrimination of letter forms. Perception \& Psychophysics, 36, 225-233.

(Manuscript received February 28, 1986; revision accepted for publication August 4, 1986.) 